Metagenomic next-generation sequencing reveals Miamiensis avidus (Ciliophora:

Scuticociliatida) in the 2017 epizootic of leopard sharks (Triakis semifasciata) in

\title{
San Francisco Bay, California
}

Hanna Retallack ${ }^{1}$, Mark S. Okihiro*2, Elliot Britton ${ }^{3}$, Sean Van Sommeran ${ }^{4}$, Joseph L. $\operatorname{DeRisi}^{1,5}$

${ }^{1}$ Department of Biochemistry and Biophysics, University of California San Francisco, $17004^{\text {th }}$ St., San Francisco, CA 94158

${ }^{2}$ Fisheries Branch, Wildlife and Fisheries Division, California Department of Fish and Wildlife, 1880 Timber Trail, Vista, CA 92081

${ }^{3}$ San Francisco University High School, 3065 Jackson St., San Francisco CA 94115

${ }^{4}$ Pelagic Shark Research Foundation, 750 Bay Ave. \#2108, Capitola CA 95010

${ }^{5}$ Chan-Zuckerberg Biohub, 499 Illinois St., San Francisco, CA 94158

${ }^{*}$ Corresponding author:

Mark S. Okihiro

California Department of Fish and Wildlife

Wildlife and Fisheries Division, Fisheries Branch

1880 Timber Trail

Vista, California 92081

Phone: (760) 310-4212

Email: Mark.Okihiro@wildlife.ca.gov

Word count: 4042 


\section{ABSTRACT}

During March to August of 2017, hundreds of leopard sharks (Triakis semifasciata) stranded and died on the shores of San Francisco Bay, California, USA. Similar mass stranding events occurred in 1967 and 2011, yet analysis of these epizootics was incomplete and no etiology was confirmed. Our investigation of the most recent epizootic revealed severe meningoencephalitis in stranded sharks, raising suspicion for infection. On this basis, we pursued a strategy for unbiased pathogen detection using metagenomic next-generation sequencing followed by orthogonal validation and further screening. We show that the ciliated protozoan pathogen, Miamiensis avidus, was present in the central nervous system of leopard $(n=12)$ and other shark species $(n=2)$ that stranded in San Francisco Bay, but absent in leopard sharks caught elsewhere. Whereas this protozoan has previously been implicated in devastating outbreaks in teleost marine fish, our findings represent the first report of a ciliated protozoan infection in wild elasmobranchs. This discovery highlights the benefits of adopting unbiased metagenomic sequencing in the study of wildlife health and disease.

\section{KEY WORDS}

epizootic, leopard shark, meningoencephalitis, metagenomic next-generation sequencing, Miamiensis avidus, San Francisco Bay, scuticociliate, Triakis semifasciata 


\section{INTRODUCTION}

Mass mortality events among wildlife populations provide insight into ecosystem health and human impact. Rapid die-offs can be caused by physical (e.g. weather), chemical (e.g. toxins), and biological processes (e.g. infectious disease), and may be precipitated by human activity. Further, the underlying cause or the indirect consequences of the die-off itself can pose a risk to human populations. Yet identifying an etiology is often challenging. Conventional approaches to epizootic investigation include environmental assessment, observation of animal behavior, and necropsy with cytology, histology, microbiological and chemical analyses. More recently, for outbreaks of infectious disease, molecular techniques like PCR have enabled rapid and specific pathogen identification. However, PCR tests specific candidates and may be limited by available genetic information. Metagenomic next-generation sequencing (mNGS) provides an unbiased alternative, which has been used successfully in human and animal infections (Dervas et al. 2017; Dill et al. 2017; Langelier et al. 2017; Pfaff et al. 2017; Wilson et al. 2017; Doan et al. 2016; Zylberberg et al. 2016; Wilson et al. 2015; Masuda et al. 2014; Stenglein et al. 2014; Wilson et al. 2014; Stenglein et al. 2012; Kistler et al. 2008). Through the analysis of all nucleic acids in a sample, mNGS can simultaneously test for all known organisms, and can also identify novel pathogens including distantly related species. Furthermore, the cost of NGS technologies continues to decrease, making these methods an increasingly viable option for routine wildlife surveillance and disease investigations. 
In the past 50 years, several die-offs of unknown etiology have affected leopard sharks (Triakis semifasciata) in San Francisco (SF) Bay, California. In 1967, over 1,000 dead sharks, mainly leopard sharks, were collected in one month in Alameda (Russo and Herald 1968; Russo 2015). More recently, unusual shark deaths were noted in the spring of 2006 (Ota and Media News Staff 2006), and mass mortality again afflicted SF Bay leopard sharks in the spring and early summer of 2011 (Prado 2011; Mertens 2011) involving likely hundreds of leopard sharks though the event was not systematically documented. Moribund sharks were often described as confused and disoriented, with erratic behaviors and swimming patterns.

Scuticociliates are free-living marine protozoa that belong to the subclass Scuticociliatida of the phylum Ciliophora (Gao et al. 2016). As opportunistic pathogens, several species of scuticociliates have been reported to cause disease in diverse marine teleost fish species (Budiño et al. 2011; Munday et al. 1997; Jung, Kitamura, and Song 2005; Moustafa et al. 2010; Iglesias et al. 2001; Whang, Kang, and Lee 2013; Smith et al. 2009; Anderson et al. 2009; Garza et al. 2017; Jung et al. 2011; Turgay and Steinum 2015; Ramos et al. 2007), and recently, in the subclass of cartilaginous fish known as elasmobranchs that includes sharks and rays (Stidworthy et al. 2014; Li et al. 2017). Scuticociliatosis is an economically important problem in the context of commercial marine fish culture (Budiño et al. 2011; Munday et al. 1997; Smith et al. 2009), but has not been observed in wild fish populations to our knowledge. 
In this study, we sought to identify a cause for mass mortality of leopard sharks in SF Bay in the spring of 2017. Using mNGS and confirmatory molecular and histologic assays, we identify the scuticociliate Miamiensis avidus ( $M$. avidus) in the central nervous system of stranded sharks, suggesting that this pathogen could contribute to significant disease in wild elasmobranchs.

\section{MATERIALS AND METHODS}

\section{Shark stranding surveillance}

The majority of shark and ray strandings were reported to the California Department of Fish and Wildlife (CDFW) by members of the public, often via The Marine Mammal Center (Sausalito, CA) and the Pelagic Shark Research Foundation (Santa Cruz, CA). Additional stranding data were provided by East Bay Regional Park District rangers (Oakland, CA), the National Parks Service, and CDFW wardens working in and around San Francisco Bay. Some data were gleaned from iNaturalist (www.iNaturalist.org). Stranding data were also acquired during three brief foot surveys of the Foster City shoreline conducted by CDFW in April, June, and August of 2017. Stranding data included date, location, species, approximate size, condition (live, dead, autolyzed), and abnormal behavior (e.g., swimming in circles). Photos were often submitted, with occasional videos. Stranding data were recorded and sorted on the basis of species and date. Shark and ray strandings were plotted on a map of south San Francisco Bay (Figure S1). 


\section{Sample collection}

Stranded sharks for necropsy by a CDFW pathologist were chosen based on condition, with preference given to live moribund and fresh dead sharks (non-autolyzed with red gills). Sharks were either necropsied in the field or iced and necropsied at CDFW in Vista, CA within 72 hours of collection. Heads of some leopard sharks were removed and frozen at $-10^{\circ} \mathrm{C}$ until necropsy. Two additional captive sharks were necropsied: one Pacific angelshark (Squatina californica) on display at the Aquarium of the Bay (San Francisco, CA), and one moribund leopard shark on display at the Marine Science Institute (Redwood City, CA). As controls, grossly normal leopard sharks were collected via gill net from Newport Bay in Southern California. An additional great white shark (Carcharodon carcharias) and soupfin shark (Galeorhinus galeus) were collected from outside SF Bay.

\section{Necropsy}

Sampled sharks were cleaned of external mud and debris via freshwater spray. Species and sex were determined via examination of fins and dentition. Sharks were weighed; total and fork length determined. The dorsum of the head was cleaned and disinfected with multiple passes using disposable Clorox Disinfecting Wipes $\AA^{\circledR}$. When possible, endolymphatic pores were identified. The endolymphatic fossa (oval concave depression in the chondrocranium) was located by digital palpation. Using sterilized instruments, a $3 \times 5 \mathrm{~cm}$ incision was made centered on the endolymphatic fossa and pores. Subcutaneous tissues, overlying the fossa, were sampled with a sterile cotton 
swab for microbiologic assessment. Subcutaneous fluid was aspirated with a sterile $1 \mathrm{~mL}$ pipette for cytological assessment. The skin sample containing the endolymphatic pores and ducts was fixed in 10\% formalin. The calvarium, including the endolymphatic fossa, was removed with a sterile scalpel and new blade, then fixed in formalin. Removal of the calvarium exposed both inner ears and the cerebellum. Cerebrospinal fluid (CSF) overlying the cerebellum was sampled with a sterile cotton swap. Two $1 \mathrm{~mL}$ CSF samples were taken by sterile pipette and frozen at $-10^{\circ} \mathrm{C}$ in cryovials. A third CSF sample was taken for cytological assessment. Perilymph from one inner ear was sampled with a sterile cotton swab. A second perilymph sample was taken for cytological assessment. The brain and olfactory lamellae were exposed via sharp dissection. The meninges, CSF, brain, inner ears, and olfactory lamellae were examined for evidence of inflammation and hemorrhage. Brains were separated from the chondrocranium via inversion of the skull and severing cranial nerves. Olfactory lamellae and associated olfactory bulbs were removed via sharp dissection. The brain and olfactory lamellae were fixed in $10 \%$ formalin. In some sharks, one otic capsule was also taken and fixed in formalin. Gills, heart, kidneys, and abdominal organs were also examined at necropsy. Selected organs were sampled and fixed in formalin from some sharks.

\section{Cytology}

Samples of subcutaneous fluid surrounding the endolymphatic ducts, inner ear perilymph, and CSF were examined on glass slides under darkfield light microscopy at 
200 and 400X using a binocular microscope. Red blood cells, inflammatory cells, and microbial pathogens were identified.

\section{Histology}

Histology samples were immersion fixed in $10 \%$ formalin for 2 weeks to 3 months and then routinely paraffin processed. Paraffin blocks were sectioned at 5-7 $\mu \mathrm{m}$ and sections stained with hematoxylin and eosin $(\mathrm{HE})$, then examined with light microscopy for inflammation, necrosis, and pathogen presence.

\section{Microbiology}

Samples of subcutaneous fluid surrounding the endolymphatic ducts, inner ear perilymph, and CSF were plated onto blood agar (for bacterial pathogens) and Sabouraud-Dextrose agar (for fungal pathogens). Cultures were incubated aerobically at room temperature $\left(15-20^{\circ} \mathrm{C}\right)$ for 4 weeks and checked daily for growth. Selected isolates were sent to the University of Florida (Gainesville, FL) for biochemical and PCR identification.

\section{Nucleic acid extraction}

For RNA, 250 $\mu \mathrm{L}$ of CSF was placed in TRI-Reagent (Zymo Research) and homogenized with $2.8 \mathrm{~mm}$ ceramic beads (Omni) on a TissueLyser II (Qiagen) at $15 \mathrm{~Hz}$ for two $30 \mathrm{sec}$ pulses, separated by 1 min on ice. Total RNA was then extracted using the Direct-Zol RNA MicroPrep Kit with DNase treatment (Zymo Research), eluted in $12 \mu \mathrm{L}$ and stored at $-80^{\circ} \mathrm{C}$ until use. For DNA, $250 \mu \mathrm{L}$ of CSF was placed in $750 \mu \mathrm{L}$ Lysis 
Solution of the Fungal/Bacterial DNA kit (Zymo Research) and homogenized as above with a single $2 \mathrm{~min}$ homogenization pulse. Total DNA was then extracted using the Fungal/Bacterial DNA kit (Zymo Research), eluted in $25 \mu \mathrm{L}$, and stored at $-80^{\circ} \mathrm{C}$ until use.

\section{Sequencing library preparation}

RNA samples were processed using $5 \mu \mathrm{L}$ total RNA as input into the NEBNext Ultra II RNA Library Prep Kit for Illumina (New England Biolabs). Samples were sequenced on an Illumina MiSeq instrument using 150 nucleotide (nt) paired-end sequencing. A "notemplate control" (nucleic acid-free water) was included in each batch of nucleic acid extractions and library preparation. Raw sequencing reads were deposited at the National Center for Biotechnology Information (NCBI) Sequence Read Archive (SRA) under BioProject PRJNA438541, SRA accession SRP136047.

\section{PCR/Sanger sequencing}

Primers used to amplify ciliate and shark genomic sequences are listed in Table S3.

PCRs were performed in a final volume of $50 \mu \mathrm{L}$ containing $1 \mathrm{X}$ Phusion HF buffer (New England Biolabs), $0.2 \mathrm{mM}$ dNTPs, $0.5 \mu \mathrm{M}$ each primer, $1 \mathrm{U}$ of Phusion DNA polymerase (New England Biolabs) and template DNA (1 $\mu \mathrm{L}$ of extracted DNA for FISH5.8SF/FISH28SR reactions, $2 \mu \mathrm{L}$ for OX09-26/OX09-27, or $5 \mu \mathrm{L}$ for Cil3/Cil4 reactions). Samples were denatured for $1 \mathrm{~min}$ at $98^{\circ} \mathrm{C}$, then cycled with $10 \mathrm{sec}$ denaturation at $98^{\circ} \mathrm{C}, 15 \mathrm{sec}$ annealing, and $30 \mathrm{sec}$ extension at $72^{\circ} \mathrm{C}$, followed by a final 5min extension at $72^{\circ} \mathrm{C}$. For primer pairs (i) FISH5.8SF/FISH28SR (Pank et al. 2001), 
(ii) OX09-26/OX09-27 (Whang, Kang, and Lee 2013), and (iii) Cil3/Cil4 (Jung, Kitamura, and Song 2005), annealing temperatures were (i) $72^{\circ} \mathrm{C}$, (ii) $55^{\circ} \mathrm{C}$, and (iii) $52^{\circ} \mathrm{C}$, extension times were (i) 2min, (ii) 30sec, and (iii) 30sec, and (i) 30, (ii) 35, or (iii) 35 cycles were performed. Nested PCR was performed with $1 / 150^{\text {th }}$ of purified OX0926/OX09-27 reaction products (purified with DNA Clean \& Concentrator-5 columns (Zymo Research) to remove primers), in $20 \mu \mathrm{L}$ reactions scaled from the conditions above, using ciliate species-specific primers OX09-142 through OX09-149 (Whang, Kang, and Lee 2013), with annealing temperature of $60^{\circ} \mathrm{C}$ and extension time of $30 \mathrm{sec}$, for 30 cycles. Amplified products were visualized on a 1.5\% (Cil3/4 and ciliate speciesspecific reactions) or 1\% (FISH5.8SF/FISH28SR and OX09-26/OX09-27 reactions) agarose gel stained with GelRed (BakerBiotium) under UV light. Purified PCR products from OX09-26/OX09-27 and Cil3/Cil4 reactions were sequenced via the Sanger method by QuintaraBio (Albany, CA).

\section{Bioinformatics}

\section{Metagenomic Next-Generation Sequencing (mNGS)}

Next-generation sequencing data were analyzed using a computational pipeline originally developed by the DeRisi Laboratory to identify potential pathogens in human samples (Michael R. Wilson et al. 2014). Briefly, host sequences were identified using publicly available shark genome/transcriptomes, and remaining non-host sequences were compared to the NCBI nucleotide and protein databases. Potential pathogens were identified based on a minimum read abundance, likelihood of pathogenicity, and 
absence in negative control samples. For species determination, reads mapping to the ciliate $18 \mathrm{~S}$ small subunit (SSU) and $28 \mathrm{~S}$ large subunit (LSU) of the nuclear ribosomal RNA locus (rDNA) were assembled and compared to the NCBI database using BLASTn (Altschul et al. 1990). See Supplemental Methods for details.

\section{Phylogenetic sequence analysis}

New sequences in this study include the partial sequences of the mitochondrial (mt) cytochrome c oxidase I (cox1) gene of ciliates from seven shark samples (by Sanger, labeled by Fish ID); the SSU rDNA sequence (by Sanger - deposited sequence is $100 \%$ identical to sequences from five shark samples, and additional consensus contigs from NGS); and the LSU rDNA (consensus contigs from NGS), deposited in GenBank (Accession numbers MH078243-MH078249, MH062876, MH064355). For comparison, cox1, SSU, and LSU sequences of representative philasterid species (Tables S4-S6) were downloaded from GenBank and aligned with the sequences identified in this study using Geneious (Biomatters Ltd, v9.1.8). Trimming ends to the shortest common region gave a total of 643,958 , and 1,799 sites for cox 1, SSU, and LSU respectively, which were used to construct NJ phylogenetic trees in Geneious (Biomatters Ltd, v9.1.8) using the Tamura-Nei distance method with Tetrahymena pyriformis as an outgroup. The confidence estimates in the NJ phylogenetic trees were determined by 1000 bootstrap re-samplings. 


\section{RESULTS}

\section{Stranded leopard sharks display inflammatory meningoencephalitis}

Beginning in March 2017, members of the public reported sharks swimming with unusual behaviors and stranding on beaches along the SF Bay shoreline, with the majority of strandings occurring in the Foster City area (Figure S1). Leopard sharks were observed swimming unusually close to shore, appearing uncoordinated and disoriented, suggestive of an inner ear or central nervous system issue. At the height of the epizootic in April and May, 20-30 dead leopard sharks were being found daily along the shoreline in Foster City shoreline, and we estimated that over 1,000 leopard sharks died between March and August 2017 in SF Bay.

Necropsies were performed on 11 fresh dead or live moribund leopard sharks, and on the heads of five frozen sharks. Gross and cytological lesions were consistent with meningoencephalitis, and characterized by hemorrhage, cloudy CSF, and thickened meninges (Figure 1, Table 1, Table S1). Lesions were especially prominent in the olfactory bulbs and lobes. Olfactory lamellae, adjacent to olfactory bulbs, were often markedly hemorrhagic and inflamed. There was no gross evidence of inflammation in the subcutaneous tissues surrounding the endolymphatic ducts or inner ears, which are target organs for a common bacterial pathogen of sharks (Carnobacterium maltaromaticum) (Schaffer et al. 2013). No lesions were observed in gills, heart, or abdominal organs. Cytologic exam of CSF revealed dense mixed inflammation (mononuclear inflammatory cells and polymorphonuclear cells). No 
pathogens were observed. Conventional microbiology was uninformative: blood and

Sabouraud-Dextrose agar cultures of CSF, inner ear perilymph, and subcutaneous tissues and surrounding endolymphatic ducts yielded no growth or fungal and bacterial contaminants associated with field sampling or post-mortem colonization of tissues.

Guided by this picture of meningoencephalitis, samples of CSF were taken for molecular analysis from 15 stranded or ill-appearing sharks from SF Bay including 11 leopard sharks (Triakis semifasciata), one sevengill shark (Notorynchus cepedianus), and one soupfin shark (Galeorhinus galeus), as well as one captive leopard shark from the Marine Science Institute (Redwood City) and one captive Pacific angelshark (Squatina californica) from the Aquarium of the Bay (San Francisco) (Table 1, Table S1). Control CSF samples were collected from four grossly normal leopard sharks captured by gill net from Newport Bay in Southern California, and from two sharks with meningoencephalitis deceased in Southern or Central California: one great white shark (Carcharodon carcharias) and one soupfin shark.

\section{mNGS reveals scuticociliate sequences in cerebrospinal fluid (CSF) of stranded}

\section{sharks}

To identify potential pathogens associated with leopard shark mortality, we performed mNGS on CSF samples from five sharks exposed to SF Bay water and two sharks from elsewhere on the California coast (Table 1). Reads aligning to species in the Ciliophora phylum (taxonomy ID 5878) were identified in all five SF Bay sharks, but were absent from the no-template control and non-SF Bay sharks (Table S2). No other credible 
pathogens were identified. Sixty-four percent (64\%) of identified Ciliophora reads aligned to the ciliate rDNA locus. High-confidence contigs were assembled for the partial SSU (943nt with a gap of 310nt) and LSU (1916nt with gaps of 39nt and 56nt) rDNA, with coverage between 4 and 2545 unique reads, and nucleotide identity $>99 \%$ except at 2 loci: nt 927 of SSU ( $88 \%$ T, 10\% G) and nt 1437 of LSU (86\% T, 9\% C) (numbering per deposited sequences). The SSU contig aligned with greater confidence to Miamiensis avidus (M. avidus) than other scuticociliate species by BLASTn.

\section{Histopathology and molecular characterization supports $M$. avidus infection}

To confirm mNGS results with an orthogonal molecular approach, we amplified a variable region of the ciliate cox 1 gene from DNA extracted from CSF of these sharks. Amplification was detected in a nested PCR for M. avidus in five of five stranded sharks that were positive for M. avidus by mNGS (Figure 2A, Figure S2), and no amplification was detected in two of two sharks negative by mNGS or in the no-template control (Figure S2). The sequence of the cox1 amplicons (via the Sanger method) was most similar to other M. avidus sequences (Figure 2B).

In addition, brain and nasal tissues from nine affected sharks were examined for histopathologic evidence of ciliated protozoa. Severe inflammatory and necrotizing lesions were observed in the olfactory bulbs and lobes of the brains, in addition to severe inflammation in the olfactory lamellae (Table 1, Figure 3). Ciliated protozoan parasites, morphologically consistent with $M$. avidus, were observed in the brains of five affected sharks, and in olfactory lamellae of one shark (Table 1, Figure 3). 


\section{Presence of M. avidus is strongly associated with the SF Bay epizootic}

With evidence for $M$. avidus as a candidate pathogen, we screened nine additional leopard sharks that stranded in SF Bay in spring of 2017, compared to four grossly normal leopard sharks that were caught in a gill net in Southern California. A soupfin shark (Galeorhinus galeus) that stranded in SF Bay in July 2017 was also tested. PCR was targeted to the ciliate SSU and $\mathrm{mt} \operatorname{cox} 1$ regions, initially using universal ciliate primers (Jung, Kitamura, and Song 2005; Whang, Kang, and Lee 2013), followed by Sanger sequencing and/or species-specific nested PCR for the cox1 gene to test for the related pathogenic ciliate species: Uronema marinum, Pseudocohnilembus longsietus, and Pseudocohnilembus persalinus (Whang, Kang, and Lee 2013). For cox1, amplification specific to M. avidus was detected in nine of nine SF Bay leopard sharks (Figure 2A, Figure S3), and was not detected in the Southern California leopard sharks (Figure S4) or the SF Bay soupfin shark (Figure S2). Amplicon sequencing revealed $99.1 \%$ pairwise identity. The cox 1 sequences clustered together with reference $M$. avidus sequences on a neighbor-joining (NJ) tree (Figure 2B). For the SSU, an amplicon of the expected size was detected in three of 12 SF Bay leopard sharks and in the two SF Bay non-leopard sharks that were positive by mNGS, and was absent from four of four leopard sharks and two of two non-leopard sharks from Southern California (Figure S5). The sequences of the ciliate SSU amplicon from five sharks (LS3, LS4, LS11, S1, and S2) were $100 \%$ identical, were concordant with the regions of overlap from $\mathrm{mNGS}$, and clustered together with reference $M$. avidus sequences on a $\mathrm{NJ}$ tree (Figure S6). 


\section{DISCUSSION}

In this study, we describe an epizootic of wild leopard sharks characterized by stranding behavior and meningoencephalitis, and provide strong molecular and histological evidence that implicates the ciliated protozoan, $M$. avidus, as the candidate pathogen associated with the SF Bay mass mortality event. We identified $M$. avidus through an unbiased, NGS-based approach, which we and others have previously used in a wide range of human and non-human infectious disease investigations (Dervas et al. 2017; Dill et al. 2017; Langelier et al. 2017; Pfaff et al. 2017; Wilson et al. 2017; Doan et al. 2016; Zylberberg et al. 2016; Wilson et al. 2015; Masuda et al. 2014; Stenglein et al. 2014; Wilson et al. 2014; Stenglein et al. 2012).

Unlike our previous investigations, we encountered a technical challenge in analyzing mNGS data from a host species lacking a complete genome. To our knowledge, the leopard shark genome has not been sequenced, and thus we utilized available sequence from related species. Despite being unable to identify all host sequences using our proxy-metagenome host sequences, we were still able to identify a plausible pathogen embedded in a large amount of unrelated, unidentified host sequence. Future contributions of shotgun sequencing data including this study will improve our ability to identify sequences of unusual hosts, such as sharks, thereby improving our ability to detect novel pathogens. The need for high-quality samples to preserve RNA and minimize contamination is especially clear in the context of fish mortality, where samples may originate in the field where death is followed by rapid 
colonization and environmental exposure. When high-quality samples are unavailable, PCR offers a good alternative for pathogen identification. Among the highly-variable regions flanked by conserved sequences, such as the commonly used ribosomal RNA (SSU and LSU) and cox 1 genes, we found that $\operatorname{cox} 1$ was similar to SSU and better than LSU in discriminating between M. avidus and related pathogenic scuticociliates. This finding is consistent with reports of higher intraspecific variation of the cox1 gene (Jung et al. 2011; Budiño et al. 2011). Nonetheless, using multiple genes for molecular phenotyping can add confidence, as there remain discrepancies in the field about highly-similar taxa such as M. avidus and Philasterides dicentrarchi (Jung et al. 2011;

De Felipe et al. 2017), and there are likely sub-species divisions yet to be realized (Gao, Katz, and Song 2012).

We observed M. avidus only in sharks exposed to SF Bay water, including two wild-caught animals in captivity. The associated phenotype is consistent with other reports of ciliate infection of elasmobranchs, notable for necrotizing meningoencephalitis (Stidworthy et al. 2014; Li et al. 2017). Pathogenesis in leopard sharks likely involves a nasal route, with initial protozoal invasion of olfactory lamellae, followed by extension into the olfactory bulbs and lobes of the brain. Massive inflammation and severe encephalomalacia, associated with $M$. avidus infection, could account for the disorientation and abnormal behavior of sharks prior to stranding. Further support implicating M. avidus in these repeated die-offs comes from the necropsy of a single leopard shark that stranded in the 2011 SF Bay epizootic, which showed extensive inflammation and an abundance of unicellular ciliated protozoa 
throughout the brain (communication from S. Kubiski, veterinary pathology resident, University of California, Davis, Pathology \#11N1368 Final Report, July 1, 2011). We found no evidence of other pathogens that have been reported in elasmobranchs near the Pacific coast of North America (Schaffer et al. 2013; Méndez and Galván-Magaña 2016; Benz, Borucinska, and Greenwald 2009).

Nonetheless, the data do not exclude the possibility that $M$. avidus was not the primary or sole driver of disease and mortality. Factors such as water temperature, salinity, toxins, or other pathogens could increase susceptibility to an opportunistic infection by M. avidus (Hobbs, Cook, and Crain 2015; Carlisle and Starr 2009; Hopkins and Cech 2003). In SF Bay, leopard sharks may be especially vulnerable each spring when they aggregate in large numbers in the warm shallow waters of bays and estuaries, with greater exposure to runoff that may contain toxins or decreased salinity (Nosal et al. 2013; Hight and Lowe 2007). Notably, heavy seasonal rainfall with runoff into the bay preceded each of the spring epizootics in 2006, 2011, and 2017 (Figure S7) (NOAA National Centers for Environmental Information 2018). Although the specific exposures are unknown, it would be prudent to monitor marine fish hatcheries for scuticociliates, as outbreaks are a known issue in such settings and may pose a risk to wild marine fish stocks. Further studies are needed to clarify susceptibility factors and exposures, especially in the context of major urban centers where planned human development could prevent or mitigate negative impacts of human activity on wild marine fish. 
While this epizootic was easily noticed in SF Bay where large numbers of sharks washed up on beaches regularly surveyed by the public and wildlife researchers, scuticociliatosis may also affect elasmobranchs or other marine animals elsewhere along the California coast. Technologies to remotely monitor inaccessible areas and connect casual observers with dedicated researchers could enable better surveillance and minimize unnecessary human intrusion into wild habitats. Future investigations of mass mortality events should include $M$. avidus as a potential pathogen. We anticipate that the episode of scuticociliatosis in wild elasmobranchs described here is not an isolated event. As similar epizootics are uncovered through seasonal monitoring, future research is needed to describe the host-pathogen relationship and potential implications for nearby human populations. Although the only known ciliate parasite of humans, Balantidium coli, is far distantly related to scuticociliates (Schuster and Ramirez-Avila 2008), and there are no documented infections of mammals by scuticociliates, sport fishing and consumption of leopard sharks is common in SF Bay and the consequences of $M$. avidus ingestion are unknown. Finally, this study demonstrates the ability of mNGS to rapidly identify potential pathogens in an unbiased manner. Surveillance and disease investigations in wildlife populations will likely benefit from the incorporation of mNGS-based techniques.

\section{ACKNOWLEDGEMENTS}

We would like to acknowledge the Marine Science Institute (Redwood City, CA), the Aquarium of the Bay (San Francisco, CA), The Marine Mammal Center (Sausalito, 
CA), East Bay Regional Park District (Oakland, CA), the National Parks Service,

Jennifer Kampe, and Paige Coluccio for their assistance in this work. We would also like

to acknowledge Eric Chow and Derek Bogdanoff at the Center for Advanced

Technology (UCSF) for assistance with sequencing. This work was supported by the

Chan Zuckerberg Biohub (JD), UCSF Medical Scientist Training Program (HR), and the State of California (MO).

\section{LITERATURE CITED}

Altschul, Stephen F., Warren Gish, Webb Miller, Eugene W. Myers, and David J. Lipman. 1990. "Basic Local Alignment Search Tool." Journal of Molecular Biology 215 (3): 403-10. doi:10.1016/S00222836(05)80360-2.

Anderson, Sally A., Debbie A. Hulston, S. Margaret McVeagh, Victoria L. Webb, and Peter J. Smith. 2009. "In Vitro Culture and Cryopreservation of Uronema Marinum Isolated from Farmed New Zealand Groper (Polyprion Oxygeneios)." Journal of Microbiological Methods 79 (1): 62-66. doi:10.1016/j.mimet.2009.07.022.

Benz, George W., Joanna D. Borucinska, and Scott A. Greenwald. 2009. "First Descriptions of Early- and Middle-Stage Copepodids of Anthosoma Crassum (Dichelesthiidae: Siphonostomatoida) and Lesions on Shortfin Makos (Isurus Oxyrinchus) Infected with A. Crassum." Journal of Parasitology, January.

Budiño, Belén, Jesús Lamas, María P. Pata, Juan A. Arranz, Manuel L. Sanmartín, and José Leiro. 2011. "Intraspecific Variability in Several Isolates of Philasterides Dicentrarchi (Syn. Miamiensis Avidus), a Scuticociliate Parasite of Farmed Turbot." Veterinary Parasitology 175 (3-4): 260-72. doi:10.1016/j.vetpar.2010.10.011.

Carlisle, Aaron B., and Richard M. Starr. 2009. "Habitat Use, Residency, and Seasonal Distribution of Female Leopard Sharks Triakis Semifasciata in Elkhorn Slough, California." Marine Ecology Progress Series 380: 213-28. doi:10.3354/meps07907. 
Dervas, Eva, Jussi Hepojoki, Andrea Laimbacher, Fernando Romero-Palomo, Christine Jelinek, Saskia Keller, Teemu Smura, Satu Hepojoki, Anja Kipar, and Udo Hetzel. 2017. "Nidovirus-Associated Proliferative Pneumonia in the Green Tree Python ( Morelia Viridis )." Journal of Virology, August, JVI.00718-17. doi:10.1128/JVI.00718-17.

Dill, J A, S M Williams, J H Leary, T F F Ng, and A C Camus. 2017. "Investigation of Epizootic Papillomatosis in Bluegill Lepomis Macrochirus (Rafinesque 1810) Using next-Generation Sequencing." Journal of Fish Diseases 40 (7): 947-52. doi:10.1111/jfd.12556.

Doan, Thuy, Michael R Wilson, Emily D Crawford, Eric D Chow, Lillian M Khan, Kristeene A Knopp, Brian D O 'donovan, et al. 2016. "Illuminating Uveitis: Metagenomic Deep Sequencing Identifies Common and Rare Pathogens." Genome Medicine 8: 1-2. doi:10.1186/s13073-016-0344-6.

Felipe, Ana-Paula De, Jesus Lamas, Rosa-Ana Sueiro, Iria Folgueira, and Jose-Manuel Leiro. 2017. "New Data on Flatfish Scuticociliatosis Reveal That Miamiensis Avidus and Philasterides Dicentrarchi Are Different Species." Parasitology, May. Cambridge University Press, 1-18. doi:10.1017/S0031182017000749.

Gao, Feng, Laura A. Katz, and Weibo Song. 2012. "Insights into the Phylogenetic and Taxonomy of Philasterid Ciliates (Protozoa, Ciliophora, Scuticociliatia) Based on Analyses of Multiple Molecular Markers." Molecular Phylogenetics and Evolution 64 (2): 308-17. doi:10.1016/j.ympev.2012.04.008.

Gao, Feng, Alan Warren, Qianqian Zhang, Jun Gong, Miao Miao, Ping Sun, Dapeng Xu, Jie Huang, Zhenzhen Yi, and Weibo Song. 2016. "The All-Data-Based Evolutionary Hypothesis of Ciliated Protists with a Revised Classification of the Phylum Ciliophora (Eukaryota, Alveolata)." Scientific Reports 6 (1): 24874. doi:10.1038/srep24874.

Garza, Jimena Balli, Nathan J. Bott, Michael D. Hammond, Natalie Shepherd, and Barbara F. Nowak. 2017. "Molecular Characterisation of Miamiensis Avidus (Ciliophora: Scuticociliata) from Ranched Southern Bluefin Tuna, Thunnus Maccoyii off Port Lincoln, South Australia." Aquaculture 469 (February): 44-49. doi:10.1016/j.aquaculture.2016.11.040.

Hight, Barbara V, and Christopher G Lowe. 2007. "Elevated Body Temperatures of Adult Female Leopard Sharks, Triakis Semifasciata, While Aggregating in Shallow Nearshore Embayments: Evidence for Behavioral Thermoregulation?" Journal of Experimental Marine Biology and Ecology 352: 114-28. 
Hobbs, James, Jonathan Cook, and Patrick Crain. 2015. "Tidal Marsh Restoration Benefits Leopard Sharks (Triakis Semifasciata) in South Bay Salt Pond Restoration Project Ponds. Final Report.” http://www.southbayrestoration.org/documents/technical.

Hopkins, Todd E, and Joseph J Cech. 2003. "The Influence of Environmental Variables on the Distribution and Abundance of Three Elasmobranchs in Tomales Bay, California." Environmental Biology of Fishes 66: 279-91.

Iglesias, R, A Paramá, MF Alvarez, J Leiro, J Fernández, and ML Sanmartín. 2001. "Philasterides Dicentrarchi (Ciliophora, Scuticociliatida) as the Causative Agent of Scuticociliatosis in Farmed Turbot Scophthalmus Maximus in Galicia (NW Spain)." Diseases of Aquatic Organisms 46 (1): 4755. doi:10.3354/dao046047.

Jung, Sung-Ju, Eun-Young Im, Michaela C. Strüder-Kypke, Shin-Ichi Kitamura, and Patrick T. K. Woo. 2011. "Small Subunit Ribosomal RNA and Mitochondrial Cytochrome c Oxidase Subunit 1 Gene Sequences of 21 Strains of the Parasitic Scuticociliate Miamiensis Avidus (Ciliophora, Scuticociliatia)." Parasitology Research 108 (5). Springer-Verlag: 1153-61. doi:10.1007/s00436010-2157-7.

Jung, Sung-Ju, Shin-Ichi Kitamura, and Jun-Young Song. 2005. "Complete Small Subunit rRNA Gene Sequence of the Scuticociliate Miamiensis Avidus Pathogenic to the Flounder." Diseases of Aquatic Organisms 64: 159-62.

Kistler, Amy L, Ady Gancz, Susan Clubb, Peter Skewes-Cox, Kael Fischer, Katherine Sorber, Charles Y Chiu, et al. 2008. "Recovery of Divergent Avian Bornaviruses from Cases of Proventricular Dilatation Disease: Identification of a Candidate Etiologic Agent." Virology Journal 5 (1): 88. doi:10.1186/1743422X-5-88.

Langelier, Charles, Matt S Zinter, Katrina Kalantar, Gregory A Yanik, Stephanie Christenson, Brian O’Donovan, Corin White, et al. 2017. "Metagenomic Sequencing Detects Respiratory Pathogens in Hematopoietic Cellular Transplant Patients." American Journal of Respiratory and Critical Care Medicine 197 (4): 524-28.

Li, Wen-ta, Chieh Lo, Chen-yi Su, Hsuan Kuo, Susanne Je-han Lin, Hui-wei Chang, Victor Fei Pang, and Chian-ren Jeng. 2017. "Locally Extensive Meningoencephalitis Caused by Miamiensis Avidus ( Syn 
. Philasterides Dicentrarchi ) in a Zebra Shark." Diseases of Aquatic Organisms 126: 167-72.

Masuda, Tsuneyuki, Makoto Nagai, Hiroshi Yamasato, Shinobu Tsuchiaka, Sachiko Okazaki, Yukie Katayama, Mami Oba, et al. 2014. “Identification of Novel Bovine Group A Rotavirus G15P[14] Strain from Epizootic Diarrhea of Adult Cows by de Novo Sequencing Using a next-Generation Sequencer." Veterinary Microbiology 171 (1-2): 66-73. doi:10.1016/J.VETMIC.2014.03.009.

Méndez, O, and F Galván-Magaña. 2016. "Cestodes of the Blue Shark, Prionace Glauca (Linnaeus 1758), (Carcharhiniformes: Carcharhinidae), off the West Coast of Baja California Sur, Mexico." Zootaxa 4085 (3): 438-44.

Mertens, C. 2011. "Leopard Sharks Found Dead in Redwood Shores Lagoon." Redwood City-Woodside Patch, April 23. https://patch.com/california/redwoodcity-woodside/leopard-sharks-found-dead-inredwood-shores-lagoon.

Moustafa, Eman Moustafa Moustafa, Nahoko Tange, Akinori Shimada, and Takehito Morita. 2010. "Experimental Scuticociliatosis in Japanese Flounder (Paralichthys Olivaceus) Infected with Miamiensis Avidus: Pathological Study on the Possible Neural Routes of Invasion and Dissemination of the Scuticociliate inside the Fish Body." Journal of Veterinary Medical Science 72 (12): 1557-63. doi:10.1292/jvms.10-0214.

Munday, BL, PJ O'Donoghue, M Watts, K Rough, and T Hawkesford. 1997. "Fatal Encephalitis due to the Scuticociliate Uronema Nigricans in Sea-Caged, Southern Bluefin Tuna Thunnus Maccoyii." Diseases of Aquatic Organisms 30 (1): 17-25. doi:10.3354/dao030017.

NOAA National Centers for Environmental Information. 2018. "Climate at a Glance: Divisional Time Series." https://www.ncdc.noaa.gov/cag/divisional/time-series.

Nosal, A. P., D. C. Cartamil, J. W. Long, M. Lührmann, N. C. Wegner, and J. B. Graham. 2013. "Demography and Movement Patterns of Leopard Sharks (Triakis Semifasciata) Aggregating near the Head of a Submarine Canyon along the Open Coast of Southern California, USA." Environmental Biology of Fishes 96 (7): 865-78. doi:10.1007/s10641-012-0083-5.

Ota, Becky, and Media News Staff. 2006. "Biologists Probe Fish Deaths in Bay." East Bay Times, July 10. https://www.eastbaytimes.com/2006/07/10/biologists-probe-fish-deaths-in-bay/.

Pank, Melissa, Michael Stanhope, Lisa Natanson, Nancy Kohler, and Mahmood Shivji. 2001. "Rapid and 
Simultaneous Identification of Body Parts from the Morphologically Similar Sharks Carcharhinus Obscurus and Carcharhinus Plumbeus (Carcharhinidae) Using Multiplex PCR." Marine

Biotechnology 3 (3). Springer-Verlag: 231-40. doi:10.1007/s101260000071.

Pfaff, F., K. Schlottau, S. Scholes, A. Courtenay, B. Hoffmann, D. Höper, and M. Beer. 2017. "A Novel

Astrovirus Associated with Encephalitis and Ganglionitis in Domestic Sheep." Transboundary and Emerging Diseases 64 (3): 677-82. doi:10.1111/tbed.12623.

Prado, M. 2011. "Dead Leopard Sharks Turning up in Richardson Bay." The Marin Independent Journal, May 19. https://www.mercurynews.com/2011/05/19/dead-leopard-sharks-turning-up-in-richardsonbay/.

Ramos, Miguel Filipe, Ana Rita Costa, Teresa Barandela, Aurélia Saraiva, and Pedro N Rodrigues. 2007. "Scuticociliate Infection and Pathology in Cultured Turbot Scophthalmus Maximus from the North of Portugal." Diseases of Aquatic Organisms 74 (3): 249-53. doi:10.3354/dao074249.

Russo, R.A., and E.S. Herald. 1968. "The 1967 Shark Kill in San Francisco Bay." California Fish and Game 54: 215-16.

Russo, Ronald A. 2015. "Observations of Predation and Loss among Leopard Sharks and Brown Smoothhounds in San Francisco Bay, California." California Fish and Game 101 (2): 149-57.

Schaffer, P. A., B. Lifland, S. Van Sommeran, D. R. Casper, and C. R. Davis. 2013. "Meningoencephalitis Associated With Carnobacterium Maltaromaticum -Like Bacteria in Stranded Juvenile Salmon Sharks ( Lamna Ditropis )." Veterinary Pathology 50 (3): 412-17. doi:10.1177/0300985812441033. Schuster, Frederick L, and Lynn Ramirez-Avila. 2008. "Current World Status of Balantidium Coli." Clinical Microbiology Reviews 21 (4): 626-38. doi:10.1128/CMR.00021-08.

Smith, P. J. PJ, S. M. McVeagh, D. Hulston, S. A. Anderson, Y. Gublin, McVeagh SM, Hulston D, and Anderson SA. 2009. "DNA Identification of Ciliates Associated with Disease Outbreaks in a New Zealand Marine Fish Hatchery." Diseases of Aquatic Organisms 86 (2): 163-67. doi:10.3354/dao02113.

Stenglein, Mark D, Elliott R Jacobson, Edward J Wozniak, James F X Wellehan, Anne Kincaid, Marcus Gordon, Brian F Porter, et al. 2014. "Ball Python Nidovirus: A Candidate Etiologic Agent for Severe Respiratory Disease in Python Regius." mBio 5 (5). United States: American Society for 
Microbiology: e01484-14. doi:10.1128/mBio.01484-14.

Stenglein, Mark D, Eric Velazquez, Cheryl Greenacre, Rebecca P Wilkes, J Graham Ruby, Julia S

Lankton, Donald Ganem, Melissa A Kennedy, and Joseph L Derisi. 2012. "Complete Genome

Sequence of an Astrovirus Identified in a Domestic Rabbit (Oryctolagus Cuniculus) with

Gastroenteritis." Virology Journal 9: 1. doi:10.1186/1743-422X-9-216.

Stidworthy, M. F., M. M. Garner, D. S. Bradway, B. D. Westfall, B. Joseph, S. Repetto, E. Guglielmi, H.

Schmidt-Posthaus, and S. M. Thornton. 2014. "Systemic Scuticociliatosis ( Philasterides

Dicentrarchi ) in Sharks." Veterinary Pathology 51 (3): 628-32. doi:10.1177/0300985813492800.

Turgay, E, and T M Steinum. 2015. "An Outbreak of Scuticociliatosis in Cultured Common Dentex

(Dentex Dentex) in Turkey." Bull. Eur. Ass. Fish Pathol 104 (353).

Whang, Ilson, Hyun-Sil Sil Kang, and Jehee Lee. 2013. "Identification of Scuticociliates

(Pseudocohnilembus Persalinus, P. Longisetus, Uronema Marinum and Miamiensis Avidus) Based

on the cox1 Sequence." Parasitology International 62 (1): 7-13. doi:10.1016/j.parint.2012.08.002.

Wilson, M. R., L. L. Zimmermann, E. D. Crawford, H. A. Sample, P. R. Soni, A. N. Baker, L. M. Khan, and

J. L. DeRisi. 2017. “Acute West Nile Virus Meningoencephalitis Diagnosed Via Metagenomic Deep

Sequencing of Cerebrospinal Fluid in a Renal Transplant Patient." American Journal of

Transplantation 17 (3): 803-8. doi:10.1111/ajt.14058.

Wilson, Michael R., Samia N. Naccache, Erik Samayoa, Mark Biagtan, Hiba Bashir, Guixia Yu, Shahriar

M. Salamat, et al. 2014. "Actionable Diagnosis of Neuroleptospirosis by Next-Generation

Sequencing." New England Journal of Medicine 370 (25). Massachusetts Medical Society : 2408-

17. doi:10.1056/NEJMoa1401268.

Wilson, Michael R., Niraj M. Shanbhag, Michael J. Reid, Neel S. Singhal, Jeffrey M. Gelfand, Hannah A.

Sample, Barlas Benkli, et al. 2015. "Diagnosing Balamuthia Mandrillaris Encephalitis With

Metagenomic Deep Sequencing." Annals of Neurology 78 (5): 722-30. doi:10.1002/ana.24499.

Zylberberg, Maxine, Caroline Van Hemert, John P Dumbacher, Colleen M Handel, Tarik Tihan, Joseph L

Derisi, Caroline Van Hemert, et al. 2016. "Novel Picornavirus Associated with Avian Keratin

Disorder in Alaskan Birds." mBio 7 (4). American Society for Microbiology: e00874-16.

doi:10.1128/mBio.00874-16. 
bioRxiv preprint doi: https//doi org/10.1101/301556: this version posted April 15,2018 . The copyright holder for this preprint (which was not certified by peer review) is the author/funder, who has granted bioRxiv a license to display the preprint in perpetuity. It is made available under aCC-BY-NC-ND 4.0 International license.

Retallack et al., mNGS reveals $M$. avidus in epizootic of leopard sharks

\section{Table 1. Summary of results}

Sharks grouped by involvement in epidemic (stranded sharks from SF Bay vs. controls from Central/Southern CA).

\begin{tabular}{|c|c|c|c|c|c|c|c|c|}
\hline & \multirow{2}{*}{$\begin{array}{l}\text { Fish } \\
\text { ID }\end{array}$} & \multirow[b]{2}{*}{ Shark Species } & \multicolumn{2}{|c|}{ Stranding / Collection } & \multicolumn{2}{|c|}{ Histopathology } & \multirow{2}{*}{$\begin{array}{c}{[2]} \\
\text { mNGS } \\
\text { Ciliate }\end{array}$} & \multirow{2}{*}{$\begin{array}{c}\text { [3] } \\
\text { PCR } \\
\text { M. avidus }\end{array}$} \\
\hline & & & Date & Location & $\begin{array}{l}\text { [1] Meningo- } \\
\text { encephalitis }\end{array}$ & Protozoa & & \\
\hline \multirow{15}{*}{ 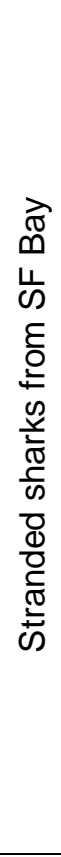 } & LS01 & Triakis semifasciata & $4 / 9 / 17$ & San Francisco & severe & Brain & $\mathrm{n} / \mathrm{a}$ & $(+)$ \\
\hline & LS02 & Triakis semifasciata & $4 / 15 / 17$ & Foster City & severe & $(-)$ & $\mathrm{n} / \mathrm{a}$ & $(+)$ \\
\hline & LS03 & Triakis semifasciata & $4 / 25 / 17$ & Foster City & severe & $(-)$ & $\mathrm{n} / \mathrm{a}$ & $(++)$ \\
\hline & LS04 & Triakis semifasciata & $4 / 25 / 17$ & Foster City & $\mathrm{n} / \mathrm{a}$ & $\mathrm{n} / \mathrm{a}$ & $\mathrm{n} / \mathrm{a}$ & $(++)$ \\
\hline & LS05 & Triakis semifasciata & $4 / 25 / 17$ & Hayward & $\mathrm{n} / \mathrm{a}$ & $\mathrm{n} / \mathrm{a}$ & $\mathrm{n} / \mathrm{a}$ & $(+)$ \\
\hline & LS06 & Triakis semifasciata & $4 / 25 / 17$ & Hayward & $\mathrm{n} / \mathrm{a}$ & $\mathrm{n} / \mathrm{a}$ & $\mathrm{n} / \mathrm{a}$ & $(+)$ \\
\hline & LS07 & Triakis semifasciata & $4 / 25 / 17$ & Hayward & $\mathrm{n} / \mathrm{a}$ & $\mathrm{n} / \mathrm{a}$ & $\mathrm{n} / \mathrm{a}$ & $(++)$ \\
\hline & LS08 & Triakis semifasciata & $4 / 26 / 17$ & Foster City & severe & Brain & $(+)$ & $(++)$ \\
\hline & LS09 & Triakis semifasciata & $4 / 26 / 17$ & Foster City & severe & Brain & $\mathrm{n} / \mathrm{a}$ & $(++)$ \\
\hline & LS10 & Triakis semifasciata & $5 / 2 / 17$ & San Francisco & severe & Brain/OL & $(+)$ & $(+)$ \\
\hline & LS11 & Triakis semifasciata & $5 / 13 / 17$ & Foster City & $\mathrm{n} / \mathrm{a}$ & $\mathrm{n} / \mathrm{a}$ & $\mathrm{n} / \mathrm{a}$ & $(++)$ \\
\hline & LS12 & Triakis semifasciata * & $5 / 23 / 17$ & MSI $\ddagger$ & severe & Brain & $(+)$ & $(++)$ \\
\hline & S1 & Squatina californica * & $5 / 17 / 17$ & AOTB $\ddagger$ & mild & $(-)$ & $(+)$ & $(++)$ \\
\hline & S2 & Notorynchus cepedianus & $5 / 17 / 17$ & San Leandro & severe & $(-)$ & $(+)$ & $(++)$ \\
\hline & S3 & Galeorhinus galeus & $7 / 5 / 17$ & Sausalito & moderate & $(-)$ & $\mathrm{n} / \mathrm{a}$ & $(-)$ \\
\hline \multirow{6}{*}{ 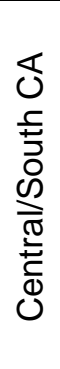 } & LS13 & Triakis semifasciata & $7 / 18 / 17$ & Newport Harbor & $\mathrm{n} / \mathrm{a}$ & $\mathrm{n} / \mathrm{a}$ & $\mathrm{n} / \mathrm{a}$ & $(-)$ \\
\hline & LS14 & Triakis semifasciata & $7 / 18 / 17$ & Newport Harbor & $n / a$ & $\mathrm{n} / \mathrm{a}$ & $n / a$ & $(-)$ \\
\hline & LS15 & Triakis semifasciata & $7 / 18 / 17$ & Newport Harbor & $\mathrm{n} / \mathrm{a}$ & $\mathrm{n} / \mathrm{a}$ & $\mathrm{n} / \mathrm{a}$ & $(-)$ \\
\hline & LS16 & Triakis semifasciata & $7 / 18 / 17$ & Newport Harbor & $\mathrm{n} / \mathrm{a}$ & $\mathrm{n} / \mathrm{a}$ & $\mathrm{n} / \mathrm{a}$ & $(-)$ \\
\hline & S4 & Carcharodon carcharias & $4 / 8 / 17$ & Santa Cruz & severe & $(-)$ & $(-)$ & $(-)$ \\
\hline & S5 & Galeorhinus galeus & $5 / 24 / 17$ & La Jolla & severe & $(-)$ & $(-)$ & $(-)$ \\
\hline
\end{tabular}

[1] Meningoencephalitis in olfactory lamellae and brain (olfactory bulbs/lobes). [2] Ciliate identified by mNGS. [3] Miamiensis avidus identified by PCR. (-) absent/negative. (+) present/positive, PCR band intensity. $\mathrm{n} / \mathrm{a}=$ assay not performed (not applicable). $\mathrm{OL}=$ olfactory lamellae. *captive shark on display in aquaria. $¥ \mathrm{MSI}=$ Marine Science Institute, located in Redwood City; AOTB = Aquarium of the Bay, located in San Francisco. 


\section{FIGURE LEGENDS}

\section{Figure 1: Gross histology and lesions in brains of stranded leopard sharks. A-B)}

Dissection from the superior aspect of the head exposing the endolymphatic ducts (arrow). C) Brain with hemorrhagic lesions removed from cranial cavity of (B) and depicted in situ in (E). D-F) Dissection of cranial vault revealing superior surface of brain, hemorrhagic lesions and congested olfactory lamellae (arrows). (OB) olfactory bulb; (OLo) olfactory lobe; (Cb) cerebellum; (OLam) olfactory lamellae. Scale bars, $2 \mathrm{~cm}$.

Figure 2: Identification of $M$. avidus in CSF from leopard sharks in SF Bay. A) DNA samples from SF Bay leopard sharks (LS1-12) and negative control animals (bat ray (BR) and S4) were tested by nested PCR using primers specific to the cox1 gene of $M$. avidus (expected size 422bp). M: 25bp ladder. B) Neighbor-joining phylogenetic tree constructed from mt cox 1 nucleotide sequences. Tetrahymena pyriformis served as the outgroup. New sequences in this study are in bold, labeled according to Fish ID (see Table 1). Nodes are labeled with bootstrap values based on 1,000 resamplings. See Table S4 for accession numbers of reference sequences. Scale bar, nucleotide substitutions per site.

Figure 3: Protozoa identified in brain tissues of stranded leopard sharks.

Representative hematoxylin and eosin stained histology sections from stranded leopard sharks. A) Olfactory lamellae (top left) and filament (center), with submucosal inflammation (bottom right) and scattered protozoa (arrow, magnified in inset). Scale 
bioRxiv preprint doi: https://doi.org/10,1101/301556; this version posted April 15,2018 . The copyright holder for this preprint (which was not certified by peer review) is the author/funder, who has granted bioRxiv a license to display the preprint in perpetuity. It is made available under aCC-BY-NC-ND 4.0 International license.

Retallack et al., mNGS reveals $M$. avidus in epizootic of leopard sharks

bars, $200 \mu \mathrm{m}$ and $25 \mu \mathrm{m}$ (inset). B-C) Olfactory bulb of the brain with congested vessels in overlying meninges (asterisks), inflammatory infiltrate, and protozoa (arrows, magnified in insets). Scale bars, $100 \mu \mathrm{m}$ and $25 \mu \mathrm{m}$ (insets). 


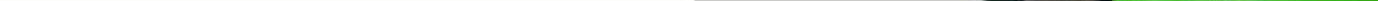

C
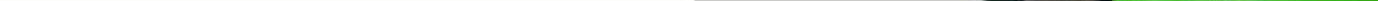


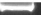

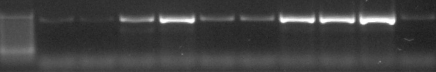

.

\section{Tetrahymena pyriformis}

\section{Uronema marinum}

100

Pseudocohnilembus longisetus

$79-$ Pseudocohnilembus persalinus $\mathrm{G}$
Pseudocohnilembus persalinus GQ

- Miamiensis avidus strain YS3

$\left.100100\right|_{\text {Sequence identified from LS12 }} ^{\text {Miamiensis avidus strain Mie0301 }}$

0.04

100 Miamiensis avidus strain YK1

100. Miamiensis avidus strain Nakajima

68..... Miamiensis avidus

53

Sequence identified from S2

100. $\begin{aligned} & \text { Miamiensis avidus strain A3 } \\ & \text { Sequence identified from S1 } \\ & \text { Sequence identified from LS11 }\end{aligned}$

59 Sequence identified from LS9

Sequence identified from LS8

Sequence identified from LS4 
